\title{
Apolipoprotein A-I, A-II, C-II, and H expression in the developing lung and sex difference in surfactant lipids
}

\author{
Pierre R Provost ${ }^{1,2,3, *}$, Eric Boucher ${ }^{1,3, *}$ and Yves Tremblay ${ }^{1,2,3}$ \\ 'Laboratory of Ontogeny and Reproduction, Rm T-2-67, Centre Hospitalier Universitaire de Québec, Pavillon CHUL, 2705 Laurier Boulevard, Québec City, \\ Québec, Canada G1V 4G2 \\ ${ }^{2}$ Department of Obstetrics and Gynecology, Faculty of Medicine, Laval University, Québec City, Québec, Canada G1V 4G2 \\ ${ }^{3}$ Centre de Recherche en Biologie de la Reproduction (CRBR), Laval University, Québec City, Québec, Canada G1V 4G2 \\ (Correspondence should be addressed to Y Tremblay; Email: yves.tremblay@crchul.ulaval.ca) \\ *(P R Provost and E Boucher contribute equally to this work)
}

\begin{abstract}
A sex difference in surfactant lipids is associated with a higher incidence of respiratory distress syndrome for males in cases of preterm birth. In animal models, the sex difference in surfactant lipids was shown to be androgen receptordependent. This report examines expression of apolipoprotein (apo)A-I, apoA-II, apoC-II, apoE, apoH, and lipoprotein lipase (LPL) by quantitative real-time PCR in pools of male and female fetal lung tissues from various mouse litters from gestation day (GD) $15 \cdot 5$ to $18 \cdot 5$, and in various adult tissues. Although the expression profiles of ApoA-I, ApoA-II, ApoCII, and $A p o H$ are complex, these genes are co-regulated and they all present a sex difference $(P=0 \cdot 0896,0 \cdot 0896,0 \cdot 0195$, and 0.0607 respectively) with higher expression for females for several litters. Pulmonary expression of apoA-I, apoA-II, and apoH were specific to the developing lung. ApoE and
\end{abstract}

LPL mRNAs showed a significant increase from GD $17 \cdot 5$ to 18.5. An increase in apoA-I-, apoA-II-, apoC-II-, and apoHmRNA accumulation was observed from GD $16 \cdot 5$ to $17 \cdot 5$ in correlation with the emergence of mature type II pneumonocytes. These four apolipoprotein genes are co-regulated with type 2 and $517 \beta$-hydroxysteroid dehydrogenases, which are respectively involved in inactivation and synthesis of androgens. Finally, apoC-II was detected by immunohistochemistry in epithelial cells of the distal epithelium. Positive signals looking like secretory granules were located near the basal membrane. Our results are compatible with a role for apolipoproteins in lipid metabolism and transport in the developing lung in association with the sex difference in surfactant lipid synthesis.

Journal of Endocrinology (2009) 200, 321-330

\section{Introduction}

Male fetuses present a transient delay in lung maturation compared with female fetuses (Nielsen \& Torday 1981, Torday \& Dow 1984, Nielsen 1985) in such a way that preterm delivery leads to a higher incidence of respiratory distress syndrome (RDS or hyaline membrane disease) in males (Farrell \& Avery 1975, Papageorgiou et al. 1981, Nielsen et al. 1982, Perelman et al. 1986a,b). Surfactant deficiency is one major cause of RDS and the surge of surfactant synthesis is normally delayed in the developing male lung when compared with the female (Nielsen \& Torday 1981, Torday \& Dow 1984, Nielsen 1985). In fact, the sex difference in surfactant production pertains to its lipid moiety (Nielsen et al. 1982, Nielsen 1985, Ballard 1989).

Fetal lung maturation leading to the surge of surfactant synthesis was delayed by androgens, both in vitro (Torday 1990) and in vivo (Nielsen et al. 1982, Nielsen 1985). Moreover, the sex difference in surfactant production was eliminated by administration of the antiandrogen flutamide, which resulted in an increase in male surfactant levels up to that of the females (Nielsen et al. 1982). This effect of androgens depends on the presence of the androgen receptor, which has been detected in human (Sultan et al. 1980), rabbit (Giannopoulos \& Smith 1982) and mouse (Provost et al. 2004) fetal lung tissues. In the mouse model of testicular feminization (Tfm mouse) in which male carriers of the X-linked Tfm mutation have no functional androgen receptors, the surfactant level of Tfm male fetuses is the same as that of normal female fetuses (Nielsen 1985). Therefore, the sex difference in the surge of surfactant synthesis is linked to higher levels of androgens in the male developing lung.

During the course of our study on lung maturation, we characterized the sex difference in the developing mouse lung by gene profiling during a gestation time window preceding and including the surge of surfactant synthesis (Simard et al. 2006). This occurs on gestation day (GD) $17 \cdot 5$ in the mouse as indicated by the appearance of lamellar bodies (Buckingham \& Avery 1962), an increase in surface activity in the mouse lung homogenate (Buckingham \& Avery 1962), and by increases in the activity of some enzymes involved in 
pulmonary lipid metabolism (Oldenberg \& Van Golde 1977, Brehier \& Rooney 1981). From the list of genes obtained by microarray hybridization experiments and presenting a sex difference in expression, two groups of genes were of particular interest. Two enzymes normally involved in glucocorticoid synthesis in adrenals constituted the first group (Simard et al. 2006). A more extensive study revealed in fact that all the genes involved in this adrenal pathway of glucocorticoid synthesis were co-expressed and co-regulated in the fetal lung on GD 15 (Provost \& Tremblay 2005). The second group of genes contained candidates involved in lipid metabolism. Four apolipoproteins, namely, apoA-I, apoA-II, apoC-II, and apoH, presented higher levels for females on GDs 15.5 and 17.5, but not on GD 16.5 (Simard et al. 2006). These results were obtained with only one pool of fetuses from one or two litters per time-point from GD $15 \cdot 5$ to $17 \cdot 5$.

Before concluding that apoA-I, apoA-II, apoC-II, and apoH are expressed with a sex difference on GD 15.5 and $17 \cdot 5$, it is essential to study more litters per time-point and to use a more quantitative technology. In the present work, quantitative real-time PCR (QPCR) was used to study expression of the above-mentioned four apolipoprotein genes in 16 litters obtained between GD 15.5 and 18.5. Because apoC-II is the essential cofactor of lipoprotein lipase (LPL), expression of the latter enzyme was also studied. ApoE, which had not been shown to present a sex difference using the microarray technology, was also included in this study. Expression of the selected genes was compared between fetal and adult tissues. Finally, apoC-II was localized by immunohistochemistry (IHC) in GD 17.5 fetal mouse lungs.

\section{Materials and methods}

\section{Animals}

Protocols were approved by the Animal Care and Use Committee and the Institutional Review Board of the Centre de Recherche du Centre Hospitalier Universitaire de Québec (protocols no. 2002-080 and 2005-091). Balb/C mice (Charles River Laboratories St-Constant SA, St-Constant, Qc, Canada) were mated during the night (mating window $\pm 8 \mathrm{~h}$ ), and the day when the copulatory plugs appeared was considered as GD 0.5. Animals did not receive any treatment. Pregnant females were killed by exposure to a $\mathrm{CO}_{2}$ atmosphere. The fetal sex was identified by examination of the genital tract using a dissecting microscope at a magnification of $\times 15$. For each litter, fetal lung tissues were pooled separately for males and females and kept frozen until RNA extraction. It should be noted that twelve of the litters were used in our previous study on type 2 and type 5 $17 \beta$-hydroxysteroid dehydrogenase (17 $\beta$-HSD) expression in the developing lung (Provost et al. 2004). Identification numbers of litters were conserved to facilitate comparison and discussion.
RNA extraction, $c D N A$ synthesis, and quantitative real-time PCR

RNA extraction, cDNA synthesis, and QPCR were performed as described (Provost \& Tremblay 2005). Briefly, total RNA extracts were prepared from each pool of tissues and then purified on $\mathrm{CsCl}$ gradients. An aliquot of $4 \mu \mathrm{g}$ total RNA was treated with DNase I $(0.25 \mathrm{U} / \mu \mathrm{g}$ total RNA $)$ and reverse transcribed (SuperScript II, Invitrogen Life Technologies, Inc.) according to the protocol of the manufacturer, using hexameric random primer $\left(\mathrm{pd}(\mathrm{N})_{6}\right.$, Invitrogen Life Technologies Inc.) in a final volume of $20 \mu$ l. LightCyclerFastStart DNA Master SYBR Green I kits (Roche) were used for QPCR. Reactions were performed according to the protocol of the manufacturer with $0.5 \mu \mathrm{M}$ of each primer (final concentration), $3 \mathrm{mM} \mathrm{MgCl}$, the indicated primers (Table 1) and an amount of cDNA samples corresponding to $100 \mathrm{ng}$ of the total RNA input in a final volume of $20 \mu \mathrm{l}$. After enzyme activation $\left(10 \mathrm{~min}, 95^{\circ} \mathrm{C}\right), 35-45$ PCR cycles were performed: $5 \mathrm{~s}$ at $95^{\circ} \mathrm{C}, 5 \mathrm{~s}$ at the annealing temperature (Table 1), $20 \mathrm{~s}$ at $72{ }^{\circ} \mathrm{C}$, and $5 \mathrm{~s}$ at the temperature of fluorescence intensity reading (Table 1). At the end of each run, samples were heated to $95^{\circ} \mathrm{C}$ with a temperature transition rate of $0 \cdot 2{ }^{\circ} \mathrm{C} / \mathrm{s}$ to construct dissociation curves. For each gene, several PCRs were tested on a $2 \%$ agarose gel, and amplicons were subjected to DNA sequencing to confirm the specificity of the PCRs. For all the analyzed genes, the amplicons encompass at least one intron. A standard curve for QPCR was prepared for each gene using specific amplicons previously obtained by PCR, sequenced, and calibrated by electrophoresis on an agarose gel. Serial dilutions of standards were prepared in $0 \cdot 1 \times$ reverse transcriptase buffer $(0 \cdot 1 \times$ : $5 \mathrm{mM}$ Tris- $\mathrm{HCl}, \mathrm{pH} 8 \cdot 3,7 \cdot 5 \mathrm{mM} \mathrm{KCl}$, and $0.3 \mathrm{mM} \mathrm{MgCl}_{2}$ ) to ensure that QPCR efficiencies of samples and standards are similar (Simard et al. 2007). The program supplied by the manufacturer (LightCycler software, version 3.5) was used to import the standard curves and calculate the amount of QPCR products (in nanograms of double-stranded cDNA). There was one pool of tissues for each sex and each litter. Therefore, the data are presented for each litter separately $(n=1)$, both the mean and the S.D. were calculated from a technical duplicate. The amount of mRNA molecules per 100 ng total RNA input was calculated from the amount of specific cDNA (nanograms) obtained by QPCR and the molecular weight of each double-stranded specific cDNA sequence. The amounts of mRNA molecules presented in Table 4 and in the text are not normalized for the efficiency of reverse transcriptase reactions.

\section{Normalization}

QPCR values obtained for the five apolipoproteins and LPL were normalized for the amount of RNA input for each sample using a set of normalization factors obtained as follows. First, expression of glyceraldehyde-3-phosphate dehydrogenase (Gapdh), succinate dehydrogenase complex subunit A flavoprotein (Sdha), and hypoxanthine guanine 
Table 1 Mouse genes analyzed and real-time PCR conditions

\begin{tabular}{|c|c|c|c|c|c|}
\hline & $\begin{array}{l}\text { GenBank accession } \\
\text { number }\end{array}$ & $5^{\prime} / 3^{\prime}$ Oligonucleotides & $\begin{array}{l}\text { Amplicon size } \\
\text { (nucleotides) }\end{array}$ & $\begin{array}{l}\text { Annealing } \\
\text { temperature }\left({ }^{\circ} \mathrm{C}\right)\end{array}$ & $\begin{array}{c}\text { Acquisition } \\
\text { temperature }{ }^{\mathrm{a}}\left({ }^{\circ} \mathrm{C}\right)\end{array}$ \\
\hline \multicolumn{6}{|c|}{ Mouse gene } \\
\hline$G a p d h^{\mathrm{b}}$ & NM_008084 & $\begin{array}{l}\text { GTCGGTGTGAACGGATTTG } \\
\text { AAGATGGTGATGGGCTTCC }\end{array}$ & 215 & 61 & 85 \\
\hline$S d h a^{c}$ & NM_023281 & $\begin{array}{l}\text { ACACAGACCTGGTGGAGACC } \\
\text { CAAACGGCTTCTTCTGCTGT }\end{array}$ & 180 & 59 & 84 \\
\hline Hprt $^{\mathrm{d}}$ & NM_013556 & $\begin{array}{l}\text { AGTCCCAGCGTCGTGATTAG } \\
\text { AATCCAGCAGGTCAGCAAAG }\end{array}$ & 229 & 63 & 82 \\
\hline ApoA-I & NM_009692 & $\begin{array}{l}\text { TGTGTATGTGGATGCGGTCA } \\
\text { ATCCCAGAAGTCCCGAGTCA }\end{array}$ & 172 & 61 & 84 \\
\hline ApoA-II & NM_013474 & $\begin{array}{l}\text { AATGGTCGCACTGCTGGTAA } \\
\text { TTGGCСТTCTCСАССААATC }\end{array}$ & 144 & 61 & 82 \\
\hline ApoC-II & NM_009695 & $\begin{array}{l}\text { TGGGGTCTCGGTTCTTCCTG } \\
\text { GCCTGCGTAAGTGCTCATGG }\end{array}$ & 251 & 61 & 84 \\
\hline ApoE & NM_009696 & $\begin{array}{l}\text { ACCGСTTCTGGGATTACCTG } \\
\text { GСTGTTCСТCСАGСТССТTT }\end{array}$ & 153 & 61 & 84 \\
\hline $\mathrm{ApoH}$ & NM_013475 & $\begin{array}{l}\text { AGTGCACGGAGGAAGGAAAA } \\
\text { TTTCCGATCATGGCAAAGTG }\end{array}$ & 181 & 61 & 82 \\
\hline$L p l$ & NM_008509 & $\begin{array}{l}\text { CCAGGATGCAACATTGGAGA } \\
\text { CAACTCAGGCAGAGCCCTTT }\end{array}$ & 194 & 61 & 82 \\
\hline
\end{tabular}

\footnotetext{
${ }^{a}$ Acquisition temperature refers to the temperature of fluorescence intensity reading.

${ }^{\mathrm{b}}$ Glyceraldehyde-3-phosphate dehydrogenase.

'Succinate dehydrogenase complex, subunit A, flavoprotein.

${ }^{\mathrm{d}}$ Hypoxanthine guanine phosphoribosyl transferase 1 .
}

phosphoribosyl transferase 1 (Hprt1) was determined by QPCR for each sample (data not shown). Second, average expression stability measure $M$ was calculated for each of these housekeeping genes with the geNorm software (Vandesompele et al. 2002) using all the fetal and adult cDNA preparations. These $M$ values were $0 \cdot 859,0 \cdot 823$, and 0.753 for Gapdh, Sdha, and Hprt1 respectively. Third, one set of normalization factors was obtained by geNorm with the three housekeeping genes and used for all the analyzed genes.

\section{Statistical analysis}

For each statistical analysis, the natural logarithm of the dependent variable (expression) was used to ensure normality and homogeneous variances of the data set. To study the effects of the GD and sex parameters on the expression of each gene, two-way ANOVA with repeated measures analyses were conducted using the MIXED procedure of SAS (version 9.1.3; SAS Institute Inc., Cary, NC, USA). The day of gestation was considered as a fixed factor. To account for possible correlations between observations made from the same litter, male and female values were considered as repeated measures with compound symmetry covariance structure. Expression values between genes were compared by the Pearson's product-moment correlation coefficient using all the values from both sexes.

\section{Immunohistochemistry}

IHC was performed as described (Drolet et al. 2007). Briefly, paraffin-embedded tissue sections of $5-\mu \mathrm{m}$ thick were deparaffinized, and then rehydrated. An antigen retrieval step consisting of boiling the slides in a microwave oven for $15 \mathrm{~min}$ in a citrate buffer $(1.8 \mathrm{mM}$ citric acid, $8.2 \mathrm{mM}$ sodium citrate) was performed. Non-specific binding sites were blocked in $10 \%$ goat serum for $1 \mathrm{~h}$ at room temperature before overnight incubation at $4^{\circ} \mathrm{C}$ with, as primary antibody, an affinity purified goat polyclonal antibody raised against a peptide mapping within an internal region of apoC-II of mouse origin (1:200; Santa Cruz Biotechnology), or purified goat $\mathrm{IgG}$ (Vector Laboratories, Burlingame, CA, USA) as negative control. A biotinylated donkey anti-goat IgG antibody was used for secondary detection (1:200; Dako, Carpinteria, CA, USA) and incubated $2 \mathrm{~h}$ at room temperature. Signal detection was achieved with Vectastain Elite ABC kit (Vector) using 3-amino-9-ethyl carbazol (AEC; Sigma-Aldrich) as substrate. Slides were counterstained with Mayer's hematoxilin. Microscopy was done using Axioskop $2+$ microscope and Zeis lenses. Images were acquired using a Retiga 2000R (Q imaging) camera and Image Pro plus software (v.5.1; Media cybernetics).

\section{Results}

Real-time PCR analysis of apolipoproteins expression

Expression of apoA-I, apoA-II, apoC-II, and apoH was studied by QPCR in mouse developing lungs isolated from GDs $15 \cdot 5$ to $18 \cdot 5$. As evidenced by the results presented in Fig. 1, expression of the four apolipoprotein genes presented variations from sample to sample, but most of these variations 


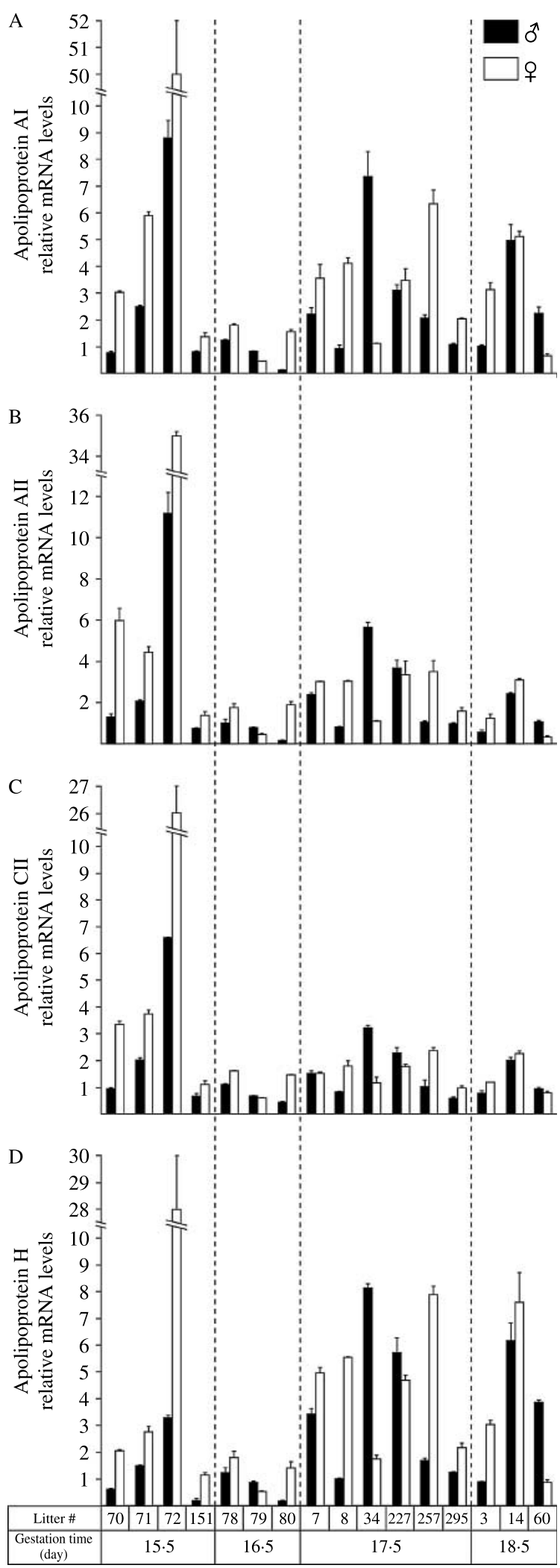

were found reproducible for each gene. Indeed, expression of the four apolipoproteins displayed the following similar points: exceptionally high expression levels for litter number 72; higher expression for females than males for the four litters on GD 15.5; higher expression for females than males for litters nos. 8 and 257, and higher expression for males than females for litter number 34 on GD 17.5. By contrast, expression levels of apoE and LPL did not present these characteristics (Fig. 2), except for litter number 257 where the female value was higher than the male value. Mean expression ( \pm s.e.m.) versus gestation time is presented for male and female fetuses for each gene (Fig. 3A). Because expression levels were very high for litter number 72 compared with the other litters, plots excluding litter number 72 are also presented (Fig. 3B). Higher expression values were obtained for females on GD 15.5 for apoA-I, apoA-II, apoC-II, and apoH, either including (see Fig. 3A) or excluding (see Fig. 3B) the values of litter number 72. As shown in Fig. 1, litter number 34 was the only one out of the six litters analyzed on GD 17.5 with a high male/female ratio. In order to appreciate the effect of this litter on the sex difference observed on GD $17 \cdot 5$, values of litter number 34 were removed and expression results were plotted again (Fig. 3C). Means from the five remaining litters presented higher expression values for females than males for apoA-I, apoA-II, apoC-II, and apoH on GD $17 \cdot 5$ (Fig. 3C). Statistical analysis was performed using all the values (i.e. those used in Fig. 3A). Results from two-way ANOVA are presented in Table 2. A significant sex difference was obtained for apoC-II $(P=0 \cdot 0195)$, while a tendency to be significant $(0 \cdot 1>$ $P>0 \cdot 05)$ was observed for all the other studied apolipoproteins. For apoA-II, the $P$ value corresponding to a change in expression between GDs tended to be significant $(P=0 \cdot 0832)$. For this gene, the $P$ values corresponding to a variation in expression from GDs $15 \cdot 5$ to $16 \cdot 5$, from GDs $16 \cdot 5$ to $17 \cdot 5$, and from GDs $17 \cdot 5$ to $18 \cdot 5$ were of $0 \cdot 0210$, $0 \cdot 0826$, and $0 \cdot 2591$ respectively. ApoE and LPL varied significantly over time (Table 2) and presented a significant increase from GD $17 \cdot 5$ to 18.5 (apoE, $P=0 \cdot 0044$; LPL, $P=0 \cdot 0003)$.

Expression levels were compared between genes by Pearson's correlation analysis (Table 3). ApoA-I, ApoA-II, ApoC-II, and $A p o H$ were co-regulated $(P<0 \cdot 00001)$, thus confirming visual examination of individual values (Fig. 1). A significant correlation was also found between apoE and LPL $(P<0 \cdot 00001)$.

Figure 1 Expression of (a) apoA-I, (b) apoA-II, (c) apoC-II, and (d) $\mathrm{apoH}$ in the developing lungs of male and female mouse fetuses of several litters between GD $15 \cdot 5$ and $18 \cdot 5$. Relative mRNA levels ( \pm s.D.) obtained by QPCR from pools of male or female lungs are presented for each indicated litter and gene. For each gene, the mean expression at GD 16.5 was fixed at one fold. Values were normalized using normalization factors calculated from expression of three housekeeping genes, as indicated in materials and methods. 


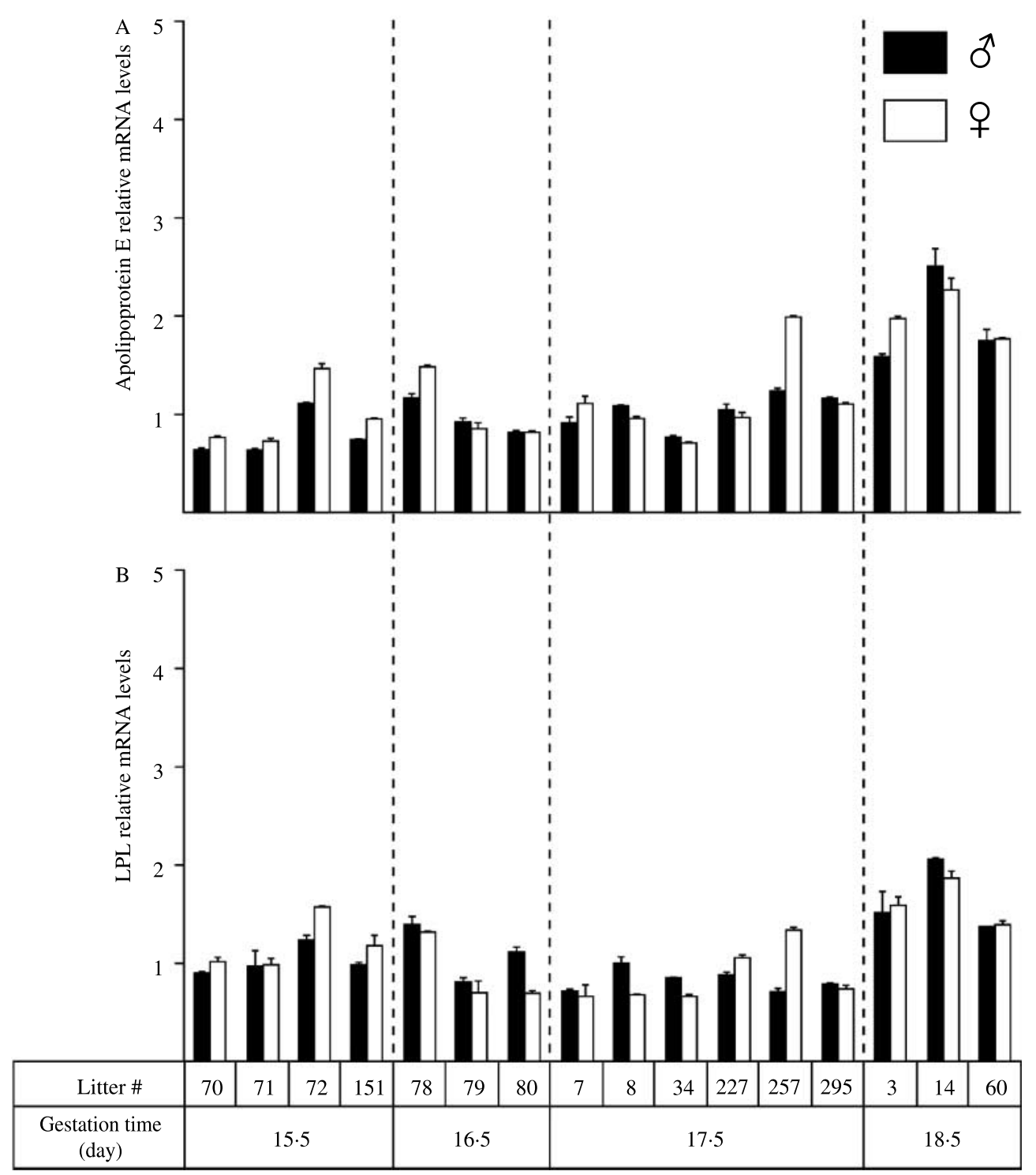

Figure 2 Expression of (a) apoE and (b) LPL in the developing lungs of male and female mouse fetuses of several litters between GD $15 \cdot 5$ and $18 \cdot 5$. Relative mRNA levels ( \pm s.D.) obtained by QPCR from pools of male or female lungs are presented for each indicated litter and gene. For each gene, the mean expression at GD 16.5 was fixed at one fold. Values were normalized as for Fig. 1.

Even though a similar pattern of expression was obtained for apoA-I, apoA-II, apoC-II, and apoH, they were not expressed at similar levels. When values calculated from the mean of expression of all male and female samples from GD $15 \cdot 5$ to $18 \cdot 5$ are used for comparison, apoA-II, apoC-II, and apoH were expressed at lower levels than apoA-I (Table 4). ApoA-I and LPL were similarly expressed, while apoE showed higher mRNA levels. Similar results were obtained when the values of litter number 72 were removed (Table 4).
Gene expression levels were compared between fetal lungs and various adult tissues. If the mean of fetal expression is fixed at $100 \%$, expression levels of only $2-6 \%$ were observed in the adult lung for ApoA-I, ApoA-II, and ApoH (Table 5). To determine whether values of litter number 72 affected these results, relative expression values were re-calculated excluding the values of litter number 72. Expression levels of 4-8\% were obtained in the adult lung for these apolipoprotein genes (data not shown). In contrast to these three apolipoprotein genes, similar or higher values were obtained 


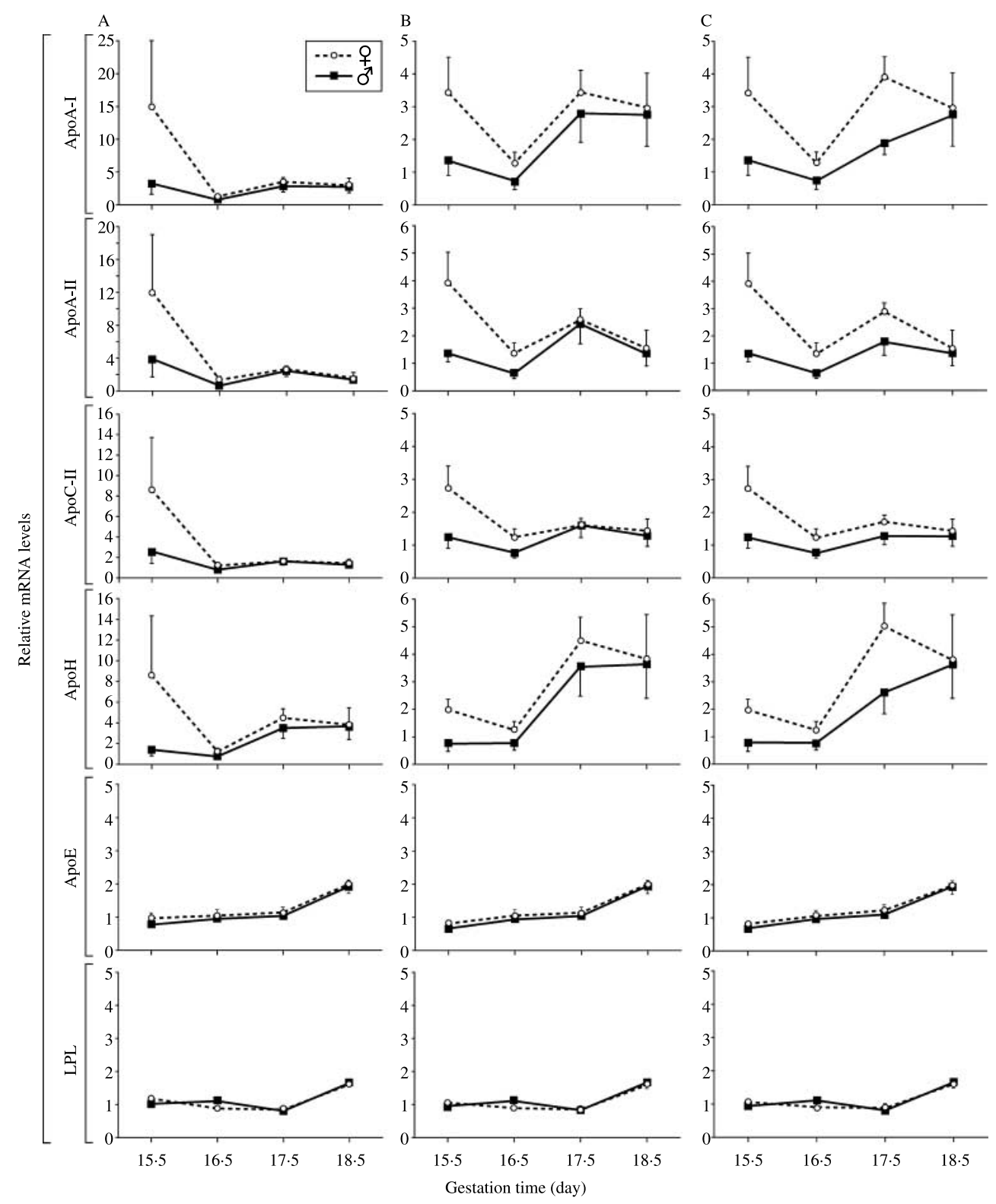

Figure 3 Levels of apoA-I, apoA-II, apoC-II, apoE, apoH, and LPL expression versus gestation time in the mouse fetal lung according to fetal sex. Means ( \pm s.E.M.) of relative mRNA levels versus gestation time (day) are presented for each fetal sex. Means were calculated using values presented in Figs 1 and 2 as follows: (A) all the values were used; (B) the values from litter number 72 were excluded; (C) the values from litters nos. 34 and 72 were excluded.

for apoC-II, apoE, and LPL in adult lungs compared with fetal lungs (Table 5). Liver and intestine are the two major tissues of lipoprotein metabolism. Apo AI mRNA levels were 25 000-30 000-fold higher in the adult liver and intestine than in the adult lung, but only 550- to 600-fold higher than in the fetal lung (Table 5). In fact, as much as $2 \cdot 5 \times 10^{7}$ copies of apoA-I mRNA molecules were detected per $100 \mathrm{ng}$ RNA input from adult liver (data not shown). Expression levels of apoA-I, apoA-II, and apoH were higher in the fetal lung than in any of the analyzed adult tissues, except the liver (and the intestine for apoA-I; Table 5).

\section{Localization of apoC-II in GD 17.5 mouse fetal lung}

The presence of apoC-II in GD 17·5-fetal lungs was studied by IHC. Positive signals for apoC-II were found in epithelial cells of the distal epithelium, while mesenchyme was negative (Fig. 4). A few cells of the proximal epithelium including 
Table 2 Statistical analysis by two-way ANOVA

\section{Analyzed variables ${ }^{\mathrm{a}}$}

$\underline{\text { Gestational day ( } P \text { values }) \quad \text { Sex }(P \text { values })}$

\section{Genes}

ApoA-I

ApoA-II

ApoC-II

$\mathrm{ApoH}$

ApoE

Lpl
$0 \cdot 0896$

0.0896

$0 \cdot 0195$

0.0607

$0 \cdot 0802$

$0 \cdot 7193$
${ }^{\mathrm{a}}$ Male and female values were considered as repeated measures.

columnar epithelial cells showed weak to moderate positive signals. Positive signals had a multiple-dot feature. These dots looked like secretory granules and most of them were located near the basal membrane, close to the mesenchyme (Fig. 4C).

\section{Discussion}

Expression of apoA-I, apoA-II, apoC-II, and apoH in the fetal lung was unexpected because they are mainly known for their association with circulating lipoproteins following their production by the liver and, for apoA-I and apoC-II, the small intestine. It was thus interesting to compare their expression in fetal and adult lung tissues and to see whether they are really expressed with a sex difference, which could contribute to explain the sex difference in surfactant lipid observed in the developing lung near the end of gestation. Despite the observed variations from sample to sample and over time, apoA-I, apoA-II, and apoH expression in the lung clearly appeared to be a developing lung characteristic, whereas apoC-II mRNA was observed in both adult and fetal lungs (Table 5). Interestingly, all these results obtained in the mouse by QPCR agree perfectly with microarray data reported for the human ((Su et al. 2004) and http://symatlas.gnf.org). Our data also show that the studied apolipoproteins are expressed

Table 3 Comparison of expression values between genes by Pearson's correlation analysis

\section{Coefficient of determination $\left(r^{2}\right)^{\mathrm{a}}$}

ApoA-I ApoA-II ApoC-II ApoH ApoE

\begin{tabular}{llllll} 
АроA-II & $0 \cdot 88^{*}$ & & & & \\
АроC-II & $0 \cdot 83^{*}$ & $0.89^{*}$ & & & \\
ApoH & $0 \cdot 84^{*}$ & $0.68^{*}$ & $0.6^{*}$ & & \\
ApoE & $0 \cdot 09$ & 0.00 & $0 \cdot 01$ & $0.18^{+}$ & \\
Lpl & 0.07 & 0.01 & 0.07 & 0.05 & $0.52^{*}$ \\
\hline
\end{tabular}

$* P<0 \cdot 00001,{ }^{+} P<0 \cdot 05$.

${ }^{\mathrm{a} A} r^{2}$ value of $1 \cdot 0$ corresponds to a perfect correlation.
Table 4 Number of specific mRNA molecules per 100 ng total RNA input in fetal mouse lungs

\begin{tabular}{|c|c|}
\hline Fetal lung & Fetal lung \\
\hline All samples ${ }^{a}$ & w/o Litter number $72^{b}$ \\
\hline
\end{tabular}

Fetal lung

Litter number 72

$\begin{array}{ll}\text { ApoA-I } & 2 \times 10^{4} \\ \text { ApoA-II } & 1 \times 10^{3} \\ \text { ApoC-II } & 3 \times 10^{3} \\ \text { ApoE } & 1 \times 10^{5} \\ \text { ApoH } & 9 \times 10^{2} \\ \text { LPL } & 1 \times 10^{4}\end{array}$

$1 \times 10^{4}$
$7 \times 10^{2}$
$2 \times 10^{3}$
$1 \times 10^{5}$
$7 \times 10^{2}$
$1 \times 10^{4}$

$1 \times 10^{5}$

$7 \times 10^{3}$

$2 \times 10^{4}$

$1 \times 10^{5}$

$4 \times 10^{3}$

$1 \times 10^{4}$

${ }^{a}$ Values are calculated from the mean of expression of all male and female samples from GD $15 \cdot 5$ to GD 18.5.

${ }^{b}$ Values are calculated from the mean expression of all samples from GD $15 \cdot 5$ to GD $18 \cdot 5$, except male and female samples from litter number 72 .

with a sex difference in late gestation ( $P$ values from 0.02 to 0.09). Such $P$ values are interesting considering that regulation over gestation time is complex and that the sex difference cannot be observed as a stable parameter over time but rather as a delay in the regulation profile. Therefore, these four apolipoproteins are candidates to explain the sex difference in surfactant lipid, although their implication in surfactant synthesis remains to be established. Our data are in agreement with a study reporting that sex differences in surfactant phospholipid content are not due to differences in phospholipid turnover (McCoy et al. 1999). Moreover, in that study, a higher level for females was observed for choline incorporation into disaturated phosphatidylcholine in mixed monolayer cultures, while no sex difference was observed with pretype II cells instead of mixed cultures. Taken together, these data and our results suggest the participation of lipoproteins secreted by lung cells in the sex difference in surfactant lipid synthesis.

Despite the complex expression profile of apoA-I, apoA-II, apoC-II, and apoH, some constants emerge. Compared to GD $16 \cdot 5$, GD $15 \cdot 5$ shows generally higher expression levels particularly for females, while GDs $17 \cdot 5$ and 18.5 present several higher values, but not systematically for females. Co-regulation of these four apolipoproteins was evidenced not only from the Pearson's correlation analysis presented in Table 3, but also by visual examination of individual values. The general expression profile, seen as male/female ratio for each litter and relative levels from litter to litter, was similar for the four apolipoprotein genes. Moreover, because many samples used in this study were also used to study expression of other genes (Provost et al. 2004), visual comparison of expression profiles strongly suggest that apoA-I, apoA-II, apoC-II, and apoH are co-regulated with type 2 and possibly type $517 \beta-H S D$ genes in the developing lung. This expression profile is not an artifact originating from the calibration of biological materials as evidenced by the expression profiles of androgen receptor (Provost et al. 2004), apoE, and $L p l$ genes (Fig. 2), which show nearly 
Table 5 Expression levels of ApoA-I, apoA-II, apoC-II, apoE, apoH, and lipoprotein lipase (LPL) in adult tissues relative to the mean of expression in fetal mouse lungs

\begin{tabular}{|c|c|c|c|c|c|}
\hline ApoA-I & ApoA-II & ApoC-II & ApoE & АрoH & LPL \\
\hline 2 & 4 & 130 & 216 & 6 & 427 \\
\hline 1 & 7 & 22 & 111 & 3 & 572 \\
\hline 58700 & 6 & 23315 & 33 & 12 & 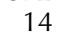 \\
\hline 73 & 6 & 143 & 276 & 3 & 166 \\
\hline 56573 & 57185 & 7099 & 3714 & 59572 & 9 \\
\hline 100 & 100 & 100 & 100 & 100 & 100 \\
\hline
\end{tabular}

constant expression levels, at least from GD $15 \cdot 5$ to $17 \cdot 5.17 \beta$ HSDs of both types 2 and 5 play a role in peripheral-tissue androgen metabolism catalyzing either their synthesis (type 5) or inactivation (type 2; Luu-The 2001). Type 2 17 $\beta$-HSD was also shown to catalyze inactivation of $17 \beta$-estradiol into estrone (Luu-The 2001) and conversion of $20 \alpha$-dihydroprogesterone into progesterone (Wu et al. 1993). Both testosterone formation through type $517 \beta-\mathrm{HSD}$ in the human type II pneumonocyte (PTII)-like A549 lung cell model (Provost et al. 2000) and testosterone inactivation through type $217 \beta-H S D$ in human lung fibroblasts (Provost et al. 2002) were observed.
The physiological relevance of apolipoprotein expression in the developing lung remains to be determined, but some hypotheses are interesting based on the fact that surfactant lipid levels present a transient sex difference near the end of gestation like expression of apoA-I, apoA-II, apoC-II, and apoH. In the mouse, the surge of surfactant synthesis occurs on GD $17 \cdot 5$. For the four apolipoproteins, profiles of expression show an increase at GD $17 \cdot 5$ compared with GD 16.5. Taken together, our results are compatible with a role in surfactant synthesis. The situation in the developing lung is unusual in that a large amount of surfactant has to be produced within a short period of time. Lipid-laden lung
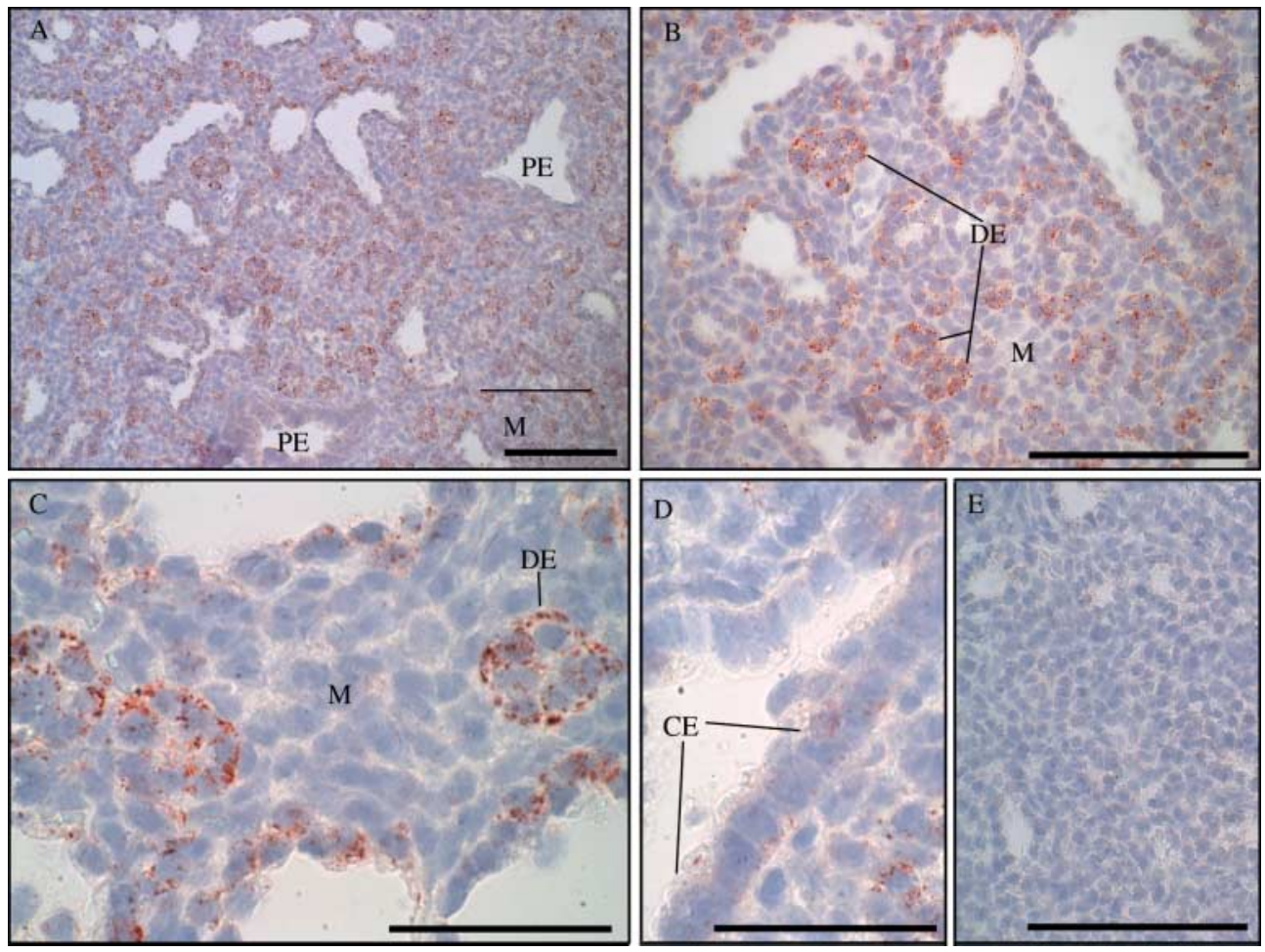

Figure 4 Localization of apoC-II by immunohistochemistry in mouse fetal lung. Mouse tissue sections are from canalicular stage lungs taken on GD $17 \cdot 5$. Tissue sections were immunostained with an anti-apoC-II antibody (A-D) or goat IgG as negative control (E). Positive signals (red) were observed in distal epithelial cells $(\mathrm{DE})$ but were absent from mesenchyme $(\mathrm{M})$. The large majority of proximal epithelial cells $(\mathrm{PE})$ were negative except for a few cells including a few columnar epithelial cells (CE) which presented weak to moderate positive signals. Magnification $\times 200(\mathrm{~A}), \times 400(\mathrm{~B}$ and E), or $\times 1000(\mathrm{C}$ and D). Scale bars, $100 \mu \mathrm{m}(\mathrm{A}, \mathrm{B}$ and E) or $40 \mu \mathrm{m}(\mathrm{C}$ and $\mathrm{D})$. 
fibroblasts (lipofibroblasts; McGowan \& Torday 1997) are transiently observed during the perinatal period in the developing lung (Maksvytis et al. 1981, Tordet et al. 1981) where they are involved in lipid storage for surfactant production by PTII cells (Nunez \& Torday 1995, Torday et al. 1995). In fact, triglyceride uptake by fibroblasts increases nine fold in the fetal rat lung between GDs 17 and 21. Both this mechanism and mobilization of fibroblast triglyceride incorporation into PTII cells-saturated phosphatidylcholine are stimulated by glucocorticoids (Nunez \& Torday 1995). Because apoA-I and apoA-II expression in the developing lung is transient like lipid accumulation in lipofibroblasts, one could suggest that these two apolipoproteins provide a mechanism for lipid transfer in interstitial fluid among lipofibroblasts, PTII cells, and plasma to support surfactant synthesis. Although lung expression of apoE is not regulated as that of apoA-I and apoA-II, apoE could also be involved in such a mechanism where it could promote apoE-containing lipoprotein internalization through the LDL receptor. Such a role could explain the observed increase in mouse apoE mRNA from GD $17 \cdot 5$ to $18 \cdot 5(P=0 \cdot 0044)$.

LPL is known to catalyze cleavage of acyl-glycerol esters in triglycerides of VLDL and chylomicrons. In the combined lipase deficiency mutation model $(c l d / c l d)$, LPL and hepatic lipase activities are very low (Blanchette-Mackie et al. 1986). Despite the presence of surfactant at birth, it was reported that lipid-containing PTII cells were not prominent in the intraalveolar septum of $\mathrm{cld} / \mathrm{cld}$ mice, in contrast to unaffected mice (Blanchette-Mackie et al. 1986), which is in line with the requirement of LPL for optimal surfactant phospholipid synthesis. We have observed an increase in LPL mRNA levels from GD 17.5 to 18.5 (Fig. 3, $P=0.0003$ ), which is compatible with a role in surfactant phospholipid synthesis. LPL expression was observed in rat lipofibroblast cell isolates where a 20-fold increase in LPL mRNA was observed from GD 19 (term GD 22) and postnatal day 2 (Chen et al. 1998). In agreement with these observations, we show that apoC-II, which is the essential co-factor of LPL (LaRosa et al. 1970, Havel et al. 1973), is present in the distal epithelium near the basal membrane, close to fibroblasts, most probably in secretory granules (Fig. 4). $\mathrm{ApoH}$ gene was also found to be co-expressed with ApoC-II gene in the developing lung. Interestingly, apoH is a multifunctional protein that was reported to play a role in triglyceride removal from the plasma (Wurm et al. 1982) and to enhance apoC-II-activated LPL activity (Nakaya et al. 1980). Taken together, our results suggest that a sex difference in the control of LPL activity may contribute to the transient sex difference in surfactant phospholipid synthesis in the developing lung. In addition to lipofibroblasts, other cell types were also shown to express LPL in the lung (Okabe et al. 1984, Camps et al. 1991, Wade et al. 2006), which can explain why apoC-II and LPL are still expressed in the mature lung (Table 5) after the disappearance of lipofibroblasts. For example, induction of human PTII cell differentiation in vitro was associated with a marked increase in LPL mRNA levels (Wade et al. 2006).
In summary, our data show that expression of apolipoproteins in the developing lung is likely to explain, entirely or in part, the sex difference in surfactant lipids during lung development. Our findings are potentially important for the study of RDS occurring after preterm birth.

\section{Declaration of interest}

The authors declare that there is no conflict of interest that could be perceived as prejudicing the impartiality of the research reported.

\section{Funding}

This work was supported by grants IGO82995 and MOP84221 from the Canadian Institutes of Health Research (CIHR) to Y T. E B was supported by a studentship from the Strategic Training Initiative in Research in Reproductive Health Sciences (STIRRHS).

\section{Acknowledgements}

We thank Dr Manon Richard for critical reading of the manuscript.

\section{References}

Ballard PL 1989 Hormonal regulation of pulmonary surfactant. Endocrine Reviews 10 165-181.

Blanchette-Mackie EJ, Wetzel MG, Chernick SS, Paterniti JR Jr, Brown WV \& Scow RO 1986 Effect of the combined lipase deficiency mutation (cld/cld) on ultrastructure of tissues in mice. Diaphragm, heart, brown adipose tissue, lung, and liver. Laboratory Investigation 55 347-362.

Brehier A \& Rooney SA 1981 Phosphatidylcholine synthesis and glycogen depletion in fetal mouse lung: developmental changes and the effects of dexamathasone. Experimental Lung Research 2 273-287.

Buckingham S \& Avery ME 1962 Time of appearance of lung surfactant in the fetal mouse. Nature 193 688-689.

Camps L, Reina M, Llobera M, Bengtsson-Olivecrona G, Olivecrona T \& Vilaro S 1991 Lipoprotein lipase in lungs, spleen, and liver: synthesis and distribution. Journal of Lipid Research 32 1877-1888.

Chen H, Jackson S, Doro M \& McGowan S 1998 Perinatal expression of genes that may participate in lipid metabolism by lipid-laden lung fibroblasts. Journal of Lipid Research 39 2483-2492.

Drolet R, Simard M, Plante J, Laberge P \& Tremblay Y 2007 Human type 2 17beta-hydroxysteroid dehydrogenase mRNA and protein distribution in placental villi at mid and term pregnancy. Reproductive Biology and Endocrinology 530.

Farrell PM \& Avery ME 1975 Hyaline membrane disease. American Review of Respiratory Disease 111 657-688.

Giannopoulos G \& Smith SK 1982 Androgen receptors in fetal rabbit lung and the effect of fetal sex on the levels of circulating hormones and pulmonary hormone receptors. Journal of Steroid Biochemistry 17 461-465.

Havel RJ, Fielding CJ, Olivecrona T, Shore VG, Fielding PE \& Egelrud T 1973 Cofactor activity of protein components of human very low density lipoproteins in the hydrolysis of triglycerides by lipoproteins lipase from different sources. Biochemistry 12 1828-1833.

LaRosa JC, Levy RI, Herbert P, Lux SE \& Fredrickson DS 1970 A specific apoprotein activator for lipoprotein lipase. Biochemical and Biophysical Research Communications 41 57-62.

Luu-The V 2001 Analysis and characteristics of multiple types of human 17beta-hydroxysteroid dehydrogenase. Journal of Steroid Biochemistry and Molecular Biology 76 143-151. 
Maksvytis HJ, Vaccaro C \& Brody JS 1981 Isolation and characterization of the lipid-containing interstitial cell from the developing rat lung. Laboratory Investigation 45 248-259.

McCoy DM, Salome RG, Kusner DJ, Iyar SS \& Mallampalli RK 1999 Identification of sex-specific differences in surfactant synthesis in rat lung. Pediatric Research 46 722-730.

McGowan SE \& Torday JS 1997 The pulmonary lipofibroblast (lipid interstitial cell) and its contributions to alveolar development. Annual Review of Physiology 59 43-62.

Nakaya Y, Schaefer EJ \& Brewer HB Jr 1980 Activation of human post heparin lipoprotein lipase by apolipoprotein $\mathrm{H}$ (beta 2-glycoprotein I). Biochemical and Biophysical Research Communications 95 1168-1172.

Nielsen HC 1985 Androgen receptors influence the production of pulmonary surfactant in the testicular feminization mouse fetus. Journal of Clinical Investigation 76 177-181.

Nielsen HC \& Torday JS 1981 Sex differences in fetal rabbit pulmonary surfactant. Pediatric Research 15 1245-1247.

Nielsen HC, Zinman HM \& Torday JS 1982 Dihydrotestosterone inhibits fetal rabbit pulmonary surfactant production. Journal of Clinical Investigation 69 611-616.

Nunez JS \& Torday JS 1995 The developing rat lung fibroblast and alveolar type II cell actively recruit surfactant phospholipid substrate. Journal of Nutrition 125 1639S-1644S.

Okabe T, Yorifuji H, Murase T \& Takaku F 1984 Pulmonary macrophage: a major source of lipoprotein lipase in the lung. Biochemical and Biophysical Research Communications 125 273-278.

Oldenberg V \& Van Golde LMG 1977 The enzymes of phosphatidylcholine biosynthesis in the fetal mouse lung. Biochimica et Biophysica Acta 489 454-465.

Papageorgiou AN, Colle E, Farri-Kostopoulos E \& Gelfand MM 1981 Incidence of respiratory distress syndrome following antenatal betamethasone: role of sex, type of delivery, and prolonged rupture of membranes. Pediatrics 67 614-617.

Perelman RH, Engel MJ, Palta M, Kemnitz JW \& Farrell PM 1986a Fetal lung development in male and female nonhuman primates. Pediatric Research $\mathbf{2 0}$ 987-991.

Perelman RH, Palta M, Kirby R \& Farrell PM $1986 b$ Discordance between male and female deaths due to the respiratory distress syndrome. Pediatrics 78 238-244.

Provost PR \& Tremblay Y 2005 Genes involved in the adrenal pathway of glucocorticoid synthesis are transiently expressed in the developing lung. Endocrinology 146 2239-2245.

Provost PR, Blomquist CH, Godin C, Huang X-F, Flamand N, Luu-The V, Nadeau D \& Tremblay Y 2000 Androgen formation and metabolism in the pulmonary epithelial cell line A-549: expression of $17 \beta$-hydroxysteroid dehydrogenase type 5 and $3 \alpha$-hydroxysteroid dehydrogenase type 3 . Endocrinology 141 2786-2794.

Provost PR, Blomquist CH, Drolet R, Flamand N \& Tremblay Y 2002 Androgen inactivation in human lung fibroblasts: variations in levels of
$17 \beta$-hydroxysteroid dehydrogenase type 2 and $5 \alpha$-reductase activity compatible with androgen inactivation. Journal of Clinical Endocrinology and Metabolism 87 3883-3892.

Provost PR, Simard M \& Tremblay Y 2004 A link between lung androgen metabolism and the emergence of mature epithelial type II cells. American Journal of Respiratory and Critical Care Medicine 170 296-305.

Simard M, Provost PR \& Tremblay Y 2006 Sexually dimorphic gene expression that overlaps maturation of type II pneumonocytes in fetal mouse lung. Reproductive Biology and Endocrinology 425.

Simard M, Boucher E, Provost PR \& Tremblay Y 2007 Minimization of PCR efficiency differences between standards and samples through dilution of PCR amplicons in reverse transcription buffer. Analytical Biochemistry 362 142-144.

Su AI, Wiltshire T, Batalov S, Lapp H, Ching KA, Block D, Zhang J, Soden R, Hayakawa M, Kreiman G et al. 2004 A gene atlas of the mouse and human protein-encoding transcriptomes. PNAS 101 6062-6067.

Sultan C, Migeon BR, Rothwell SW, Maes M, Zerhouni N \& Migeon CJ 1980 Androgen receptors and metabolism in cultured human fetal fibroblasts. Pediatric Research 14 67-69.

Torday JS 1990 Androgens delay human fetal lung maturation in vitro. Endocrinology 126 3240-3244.

Torday JS \& Dow KE 1984 Synergistic effect of triiodothyronine and dexamethasone on male and female rat lung. Developmental Pharmacology and Therapentics 7 133-139.

Torday J, Hua J \& Slavin R 1995 Metabolism and fate of neutral lipids of fetal lung fibroblast origin. Biochimica et Biophysica Acta 1254 198-206.

Tordet C, Marin L \& Dameron F 1981 Pulmonary di-and-triacylglycerols during the perinatal development of the rat. Experientia 37 333-334.

Vandesompele J, De Preter K, Pattyn F, Poppe B, Van Roy N, De Paepe A \& Speleman F 2002 Accurate normalization of real-time quantitative RT-PCR data by geometric averaging of multiple internal control genes. Genome Biology 3 RESEARCH0034.

Wade KC, Guttentag SH, Gonzales LW, Maschhoff KL, Gonzales J, Kolla V, Singhal S \& Ballard PL 2006 Gene induction during differentiation of human pulmonary type II cells in vitro. American Journal of Respiratory Cell and Molecular Biology 34 727-737.

Wu L, Einstein M, Geissler WM, Chan HK, Elliston O \& Andersson S 1993 Expression cloning and characterization of human $17 \beta$-hydroxysteroid dehydrogenase type 2 , a microsomal enzyme possessing $20 \alpha$-hydroxysteroid dehydrogenase activity. Journal of Biological Chemistry 268 12964-12969.

Wurm H, Beubler E, Polz E, Holasek A \& Kostner G 1982 Studies on the possible function of beta 2-glycoprotein-I: influence in the triglyceride metabolism in the rat. Metabolism 31 484-486.

Received in final form 12 December 2008

Accepted 22 December 2008

Made available online as an Accepted Preprint

23 December 2008 